\title{
As Formas Elementares: ponto de redefinição da sociologia durkheimiana?
}

\section{JOSÉ BENEUIDES QUEIROZ}

\section{Resumo}

As Formas Elementares da Vida Religiosa é a última grande obra que Émile Durkheim publicou em vida. Sua importância para a sociologia, antropologia e áreas afins é inequívoca, o que fez e faz do livro um clássico das Ciências Sociais. Tal referência que passou a ser ocorreu acompanhada de determinadas avaliações e interpretações. Dentre essas, destacam-se aquelas que veem As Formas Elementares, positiva ou negativamente, como um ponto de ruptura no interior do projeto intelectual durkheimiano. O presente trabalho, tomando como referencial o conjunto da obra do sociólogo francês, e passando em revista os argumentos dos autores que identificam na obra de 1912 uma nova abordagem, mostra que a religião sempre esteve presente nas preocupações - nos planos social e científico - de Durkheim. Como será exposto, se, por um lado, a maneira de tratar o fenômeno religioso foi gradativamente se modificando, por outro, a concepção e elaboração de As Formas Elementares da Vida Religiosa não prescindiram dos recursos teóricos e metodológicos formulados e operacionalizados nas obras precedentes. Ou seja, mostrar-se-á que, ao invés de ruptura, há uma linha de continuidade entre as primeiras e aquela última obra de Émile Durkheim.

Palavras-chave: Durkheim. Positivismo. Idealismo. Sociologia da Religião.

*Universidade Federal do Maranhão (Brasil) 


\title{
The Elementary Forms of Religious Life: a turning point in Durkheimian sociology?
}

\begin{abstract}
The Elementary Forms of Religious Life was Émile Durkheim's last published masterpiece. Its importance to Sociology, Anthropology and other related areas is unequivocal, what made the book a classical in the Social Sciences. This recognition came along with certain evaluations and interpretations, among which those that, either positively or negatively, deem The Elementary Forms as a turning point in the Durkheimian intellectual project. The present paper, drawing on the complete works of the French sociologist and reviewing the arguments of scholars that identify a new approach in the 1912's work, shows that religion has always been present in Durkheim's concerns - regarding social and scientific spheres. I argue that if, on the one hand, the approach to the religious phenomenon has gradually changed, on the other hand, the conception and elaboration of The Elementary Forms did not dispense with the theoretical and methodological resources formulated and operationalized in the precedent works. In other words, this paper will show that, instead of a watershed, there is actually a continuity between Durkheim's first works and that last one.
\end{abstract}

Keywords: Durkheim. Positivism. Idealism. Sociology of religion. 


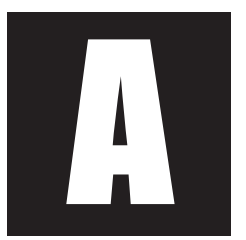

s Formas Elementares da Vida Religiosa, que data de 1912, é o último livro publicado em vida por Émile Durkheim. Como os três anteriores, ele faz parte de um projeto intelectual que almejava consolidar e fazer reconhecer - principalmente pela academia - a sociologia como um conhecimento científico. Fruto de um longo empreendimento coerente e, por isso, coeso, o livro transcendeu não só o circuito nacional francês, como foi igualmente impactante em outras áreas, como na antropologia, na história das religiões, na filosofia, etc. Isso se revela no número de resenhas e artigos publicados mundo afora, até a morte do autor, em $1917^{1}$.

Contudo, apesar de formulada no interior desse projeto intelectual, As Formas Elementares da Vida Religiosa, muitas vezes, é apropriada, compreendida e comentada como uma obra sui generis no interior da sociologia durkheimiana. Para alguns estudiosos, como mostraremos mais à frente, ela representa uma mudança de perspectiva, uma ruptura e, por isso, uma recusa do autor de suas concepções (teóricas e metodológicas), preocupações, interesses e objetivos anteriores.

Dentre os argumentos apresentados, que buscam provar a existência dessa mudança - muitas vezes diversos, antípodas e conflitantes entre si -, destaca-se a afirmação de que foi com As Formas Elementares que, pela primeira vez, Durkheim voltou suas atenções para o fenômeno religioso e o avaliou como uma dimensão importante da vida social. Ocorre que, passando em revista toda sua trajetória intelectual, é possível verificar que esse fenômeno é levado em consideração tanto na Divisão do Trabalho Social, de 1893, pois a explicação que estabelece da preponderância do

\footnotetext{
${ }^{1}$ Segundo o criterioso levantamento de Stéphane Baciocchi (2012), após a publicação do livro, até 1915, em vários países, entre resenhas e artigos, registram-se 51 que tratam de As Formas Elementares. Já depois de 1915, ano em que é publicada a tradução da obra para o inglês, até 1917, verificam-se 22.
} 
direito repressivo nas sociedades pré-modernas está vinculada à importância da religião como principal fundamento moral, quanto em O Suicídio, de 1897, no qual relaciona as taxas de suicídio, dentre outros fatores, às diferentes religiões, e em artigos e debates, como $O$ individualismo e os intelectuais, de 1898, ou a Determinação do fato moral, de 1906.

Porém, poder-se-ia argumentar que, nessas várias ocasiões, a religião não estava posta como objeto central de discussão, apesar de imprescindível nas obras e reflexões em questão. No entanto, para fazer uso recorrente da religião nos seus diversos estudos sociológicos, Durkheim não poderia estar alheio ao seu significado no interior da vida social; ou seja, não poderia só pontualmente voltar sua atenção na direção da mesma. Na verdade, paralelamente a toda sua produção sociológica, à publicação de seus principais livros, ele desenvolvia minuciosos estudos e reflexões sobre a religião. Já em 1887, na Revue Philosophique, numa extensa resenha que faz do livro de Guyau (L'irréligion de l'avenir : étude sociologique), ele afirma que

Num artigo publicado aqui mesmo, em julho último, nós expressamos o desejo de estudar a religião como um fenômeno social. Na ocasião, parecia-nos que a maior parte das teorias em voga fazia da religião um simples evento da consciência individual, desconhecendo assim o seu caráter essencial (Durkheim, 1975a, p. 149).

Este desejo começa a apresentar resultados e a materializar-se sete anos depois: no ano letivo de 1894/1895, Durkheim ministra um curso que trata das "teorias gerais sobre as formas originais da religião" (Durkheim, 1975b, p.452). No mesmo período, em artigo escrito para a revista italiana La riforma sociale, fazendo referência àquela atividade acadêmica, ele afirma que

Tendo tratado da religião num curso ainda inédito, nós não começamos perguntando o que é a ideia religiosa e o 
sentimento religioso, mas estudamos as diferentes religiões que existiram e as que ainda existem, comparamo-las, ressaltamos as suas características comuns e, assim, pudemos determinar em que consiste objetivamente o fenômeno religioso (Durkheim, 1975c, p. 97).

Esta afirmação, permeada de aspectos metodológicos, é emblemática, pois foi feita num momento crucial do projeto sociológico durkheimiano. Isso porque, como ele próprio irá afirmar anos mais tarde, em 1907,

É somente em 1895, tive a nítida percepção do papel capital jogado pela religião na vida social. Foi neste ano que, pela primeira vez, encontrei o meio de abordar sociologicamente o estudo da religião. Para mim, isto foi uma revelação. Este curso de 1895 marca uma linha divisória no desenvolvimento de meu pensamento, ainda que todas as minhas pesquisas anteriores tivessem de ser repetidas novamente para ficarem em harmonia com esses novos pontos de vista (Durkheim, 1975d, p. 404).

Isso significa, por um lado, que, mesmo não sabendo ainda como tratá-la sociologicamente, a religião estava presente desde seus primeiros estudos. Por outro, que a harmonização das pesquisas anteriores, à qual fazia referência, não significava negá-las, mas sim reposicionar a religião no interior daqueles estudos. Além disso, a partir desse marco, até a publicação de As Formas Elementares, é possível verificar uma vigorosa sistematização de suas pesquisas e análises sociológicas sobre a religião, na qual, entre resenhas e artigos, são desenvolvidos estudos sobre a natureza da religião, as relações religião/sociedade, religião/ciência, os diversos aspectos que envolvem o totemismo, a separação do Estado da Igreja, entre outros. Ao longo destes 17 anos, destacam-se o artigo Da Definição dos Fenômenos Religiosos, publicado no L'Année Sociologique, de 1897/1898, uma extensa resenha do Curso Sobre as Origens da Vida Religiosa, publi- 
cada na Revue de Philosophie, em 1907, (na qual tenta precisar uma definição do fenômeno religioso, identificar a forma mais primitiva da religião - o que exige toda uma discussão sobre a teoria animista e a teoria naturista - discutir o totemismo, bem como os ritos), e o artigo Sociologia Religiosa e Teoria do Conhecimento, publicado na Revue Métaphisique et la Morale, em 1909 (que nada mais é do que, com pouquíssimas variações e uma parte que não foi incorporada², a Introdução de As Formas Elementares).

Este coeso projeto intelectual mostra como o conjunto das obras de Durkheim não pode ser compreendido e tratado de maneira compartimentada, como é por vezes apresentado. O livro As Formas Elementares, apesar da especificidade de seu objeto e do objetivo que deseja alcançar, bem como algumas diferenças que não podem ser negadas, entrelaça-se de várias maneiras com as demais obras do autor.

No entanto, deixando de lado essa compartimentação, podemos constatar a existência de intérpretes que, embora não tomem As Formas Elementares como uma obra única, introdutora de um tema que seria, até então, alheio ao autor, avaliam que ela revela um novo tipo de abordagem sociológica, quer no plano metodológico, quer no teórico, ou até mesmo no político. Noutras palavras: ao longo dos anos que se seguiram à sua publicação, alguns autores identificaram nela um momento de ruptura no interior do pensamento durkheimiano. Tal cisão, porém, não é apontada por meio de um diagnóstico homogêneo, mas de maneiras diversas; grosso modo, ela pode ser vista negativamente, como um momento menor do autor, ou positivamente, como a ocasião em que ele dá um salto qualitativo em relação ao que até então havia produzido.

No primeiro caso, o do diagnóstico negativo, As Formas Elementares é apresentada como a expressão do ponto culminante de um projeto

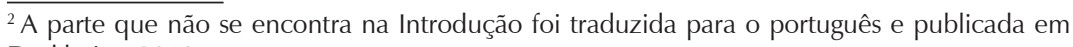
Durkheim, 2013. 
intelectual que, a princípio promissor, foi declinando e mostrando-se incapaz de enfrentar os desafios cada vez mais complexos da sociedade industrial. Esta limitação explicaria porque, pouco a pouco, a religião foi ganhando primazia nos estudos de Durkheim. Na avaliação de Bernard Lacroix e Béatrice Landerer, Durkheim foi substituindo uma "teoria do homem socializado" por uma "idealização do que socializava o homem" (Lacroix; Landerer, 1972, p.176). Era como se o método científico tivesse declinado em favor das concepções que fundamentam o pensamento religioso. Nesse caso, segundo Armand Cuvillier, em texto de 1948, a partir do artigo Representações Individuais e Representações Coletivas (1898), as interpretações de Durkheim "assumiram mais e mais um caráter idealista" e, porque não dizer, metafísico (Cuvillier,1948). Em síntese: a religião passou a ser considerada o fundamento primeiro da socialização humana e a chamada questão social, importante vetor dos primeiros trabalhos de Durkheim, relegada ao segundo plano.

Esta interpretação não é unívoca. Ela comporta outras, em direções, se não completamente opostas, no mínimo diferentes.

Uma que merece atenção e destaque é a análise elaborada por Talcott Parsons, em 1937, no seu livro A Estrutura da Ação Social. O sociólogo americano divide a obra de Durkheim em quatro estágios: o primeiro seria o momento de formação, que culmina com Da Divisão do Trabalho Social; o segundo é quando elabora "um sistema teórico geral", destacando-se aí a publicação de As Regras do Método Sociológico e O Sucídio; no terceiro, caracterizando-se como um período de transição, ele rompe com a teoria sistemática formulada anteriormente, resultando daí o texto Representações individuais e representações coletivas, publicado na Revue de Métaphysique, em 1898; o livro póstumo A Educação Moral, que reúne aulas ministradas no ano escolar 1902-1903 e publicado em 1925, e a já mencionada apresentação oral de A determinação do fato moral, feita 
na Societé Française de Philosophie; no quarto e último, "com base nesta nova posição geral, abriu-se um vasto âmbito de novos problemas que levaram a novos campos empíricos, os quais foram desenvolvidos em As Formas Elementares da Vida Religiosa (1912)" (Parsons, 2010, p.369). Um dos aspectos que marca este "processo de desenvolvimento" da teoria de Durkheim, segundo Parsons, é o seu gradativo distanciamento em relação ao positivismo. De acordo com sua interpretação, se, num primeiro momento, ele converge com a tradição positivista, principalmente face à "exigência metodológica da própria ciência", nos momentos posteriores - já em Divisão do Trabalho - ele recusa o positivismo individualista, passa a priorizar a estática social em detrimento da dinâmica social, esta defendida por Comte, e rompe em definitivo a partir da publicação de As Formas Elementares. Na avaliação de Parsons, "embora em outras conexões Durkheim já tivesse ido bem longe nessa direção, foi seu estudo da religião que completou o processo e, por assim dizer, tornou irrevogável sua ruptura com o positivismo" (Parsons, 2010, p. 485). Os dois elementos constitutivos da obra, a teoria da religião e a epistemologia, contribuem de modo decisivo para a realização desse rompimento. A teoria da religião, em razão da distinção entre o sagrado e o profano, que torna possível uma crítica do utilitarismo, e da distinção entre crenças e ritos, a qual permite compreender que as crenças nem são ilusórias nem derivam das impressões empíricas. No plano da teoria do conhecimento, na visão de Parsons, Durkheim substitui a epistemologia empirista por uma epistemologia idealista, pois, se as categorias e os conceitos têm suas origens no social, este nada mais é que um sistema de valores. 
A posição de Raymond Aron, mesmo não compartilhando da ideia da superação do positivismo, e sempre demonstrando uma explícita antipatia para com Durkheim³ ${ }^{3}$ também ressalta que há uma marca distintiva em As Formas Elementares. Para ele, em relação aos três livros anteriores, esse é "o mais importante e profundo, o mais original" (Aron, 1999, p.310). Mesmo assim, apesar deste diferencial, Aron avalia que, aí, a sociolatria é levada às últimas consequências.

No conjunto, conquanto apresentem contribuições, essas avalições parecem um tanto quanto deslocadas quando confrontadas com a toda trajetória intelectual de Durkheim, que deságua na publicação de As Formas Elementares. Ao que parece, a obra não pode representar uma ruptura, pois, como mostrado antes - e isso o próprio Parsons reconhece -, a mesma foi desenvolvida em conjunto com outras reflexões e preocupações do autor em torno da religião. Mesmo apresentando novos conceitos, refinando uns e pontualmente suprimindo outros, a obra, ao invés de destoar, encaixa-se de maneira congruente no projeto intelectual do sociólogo francês; não só no que tange a alguns aspectos teóricos e metodológicos, mas igualmente aos políticos, pois, por meio dela, a questão social, embora não seja explicitada diretamente no texto, não é perdida de vista.

Contra esta interpretação, poderia ser levantada a questão de que o próprio Durkheim, em 1895, como anteriormente citado, admite que, ao ter tido a "revelação" da importância da religião, foi obrigado a rever seus trabalhos precedentes, para colocá-los em "harmonia com esses novos pontos de vista". No entanto, a natureza dessa demarcação sugerida por Durkheim parece ser muito diferente das propostas pelos autores acima mencionados: ela sugere estabelecer um novo papel da religião no

\footnotetext{
${ }^{3}$ Como Lévi-Strauss, Aron faz parte da geração entre guerras, como bem mostra Jean-Christophe Marcel (2001), a qual desejava manter-se afastada do legado sociológico de Durkheim. Algo que evidencia esse distanciamento é o seu livro La Sociologie Allemande Contemporaine, de 1936, quando introduz Max Weber na França.
} 
interior da vida social, o que, de certo modo, abria novas perspectivas para as pesquisas por ele até então desenvolvidas. Quanto ao projeto de construção de uma ciência da sociedade, à recusa das explicações filosóficas sobre a vida social, à parte do método sociológico proposto, etc., permaneceram quase que intactos. Dito de outro modo: entre as primeiras obras e As Formas Elementares, como bem avalia Philippe Steiner, é possível verificar que há uma linha de força que foi seguida por Durkheim (Steiner, 2005, pp. 23-24).

Como uma primeira aproximação, para podermos esclarecer essa continuidade, seria interessante tentarmos observar como ocorre a relação entre As Formas Elementares e Da Divisão do Trabalho Social. Aqui, dentre outros, destacamos dois aspectos. Primeiro, há nesta última a antecipação e sugestão de vários temas que serão desenvolvidos na obra de 1912. Como lembra Giddens, em Da Divisão do Trabalho Social

Rejeita-se a ideia de que a religião pode ser definida como necessariamente relacionada com seres sobrenaturais ou com deuses. Sugere-se que as crenças religiosas expressam o caráter da totalidade social; que a religião é a fonte original de todas as formas de pensamento, que subsequentemente se secularizaram; e, finalmente, que, embora, o domínio da religião sobre a vida do dia-a-dia decline no curso da diferenciação social e as velhas divindades desapareçam, os novos ideais de individualismo moral ainda preservam um caráter intrinsecamente religioso (Giddens, 1981, p.60).

Segundo, na caracterização da sociedade que tinha o totemismo como religião, mais especificamente, na discussão dos capítulos sobre Origens dessas crenças, Durkheim toma, algumas vezes, como referência, as explicações que desenvolveu em Divisão do Trabalho. Por outro lado, As Formas Elementares contribui para a superação de uma deficiência em Divisão do Trabalho: enquanto, neste livro, é evidente o que torna possível a solidariedade orgânica - no caso, a divisão do trabalho -, o 
mesmo não ocorre quando se trata de explicar a solidariedade mecânica. Diversamente, em As Formas Elementares, suprime-se esta debilidade. De acordo com Durkheim, dentre as diversas vezes em que explica a semeIhança entre os indivíduos,

As maneiras de agir que a sociedade tem o maior interesse em impor a seus membros estão marcadas, por isso mesmo, com o sinal distintivo que provoca o respeito. Como elas são elaboradas em comum, a vivacidade com que são pensadas por cada espírito particular repercute em todos os outros e reciprocamente... É a sociedade que fala pela boca daqueles que as afirmam em nossa presença; é ela que ouvimos ao ouvi-los, e a voz de todos tem um acento que a de um só não poderia ter. A violência mesma com que a sociedade reage, por meio da censura ou da repressão material, contra as tentativas de dissidências, manifestando com estrépito o ardor da convicção comum, contribui para reforçar o seu domínio (Durkheim, 1968, p.297).

Assim, o estudo da forma mais simples de religião, o totemismo, ajuda a esclarecer a origem e os fundamentos da solidariedade mecânica, as características que assumiram as primeiras relações sociais.

Em síntese, como se pode ver, há como que uma relação pendular entre Da Divisão do Trabalho Social e As Formas Elementares; na primeira, estão esboçados traços que seriam desenvolvidos nesta última, e, por sua vez, As Formas Elementares preenche as lacunas que existiam na primeira.

Um pouco diferente e, porque não dizer, de outra natureza, é a relação entre As Regras do Método Sociológico e As Formas Elementares. Como analisa com pertinência Philippe Steiner, já em O Suicídio, as regras metodológicas recém-formuladas não são ferreamente aplicadas. ${ }^{4}$ Além disso, em As Formas Elementares, alguns procedimentos metodológicos

\footnotetext{
${ }^{4}$ Steiner, P. op. cit., pp. 40/41. Como destaca o autor, apesar de alegar que aplicará as regras anteriormente formuladas, em O Suicídio, Durkheim admite que seu estudo parte dos casos individuais.
} 
de As Regras não são utilizados, como o recurso da comparação ${ }^{5}$, bem como determinados conceitos ou quase desaparecem - que é o caso do fato social, citado apenas no plural e cinco vezes - ou são substituídos por outros - as representações coletivas abundam e ganham espaço em detrimento da consciência coletiva, a qual é citada somente quatro vezes ao longo da obra.

Mesmo assim, é possível verificar que há um aspecto metodológico que liga As Formas Elementares a As Regras do Método Sociológico e O Suicídio: trata-se da importância da delimitação do objeto a ser estudado. Durkheim ressalta a importância e detalha esse procedimento na segunda parte da segunda regra para a observação do fato social, que se encontra no segundo capítulo de As Regras do Método Sociológico (Durkheim, 1963, pp. 35-39). Como no estudo sobre o suicídio, em que a definição e a delimitação do objeto são precedidas de uma minuciosa revisão crítica das concepções então vigentes, o mesmo verificamos em As Formas Elementares, quando o autor passa em revista diversos aspectos e concepções relacionados ao fenômeno religioso para, ao término, definir seu conceito de religião e, como consequência, seu objeto de estudo.

No entanto, como insiste Parsons, outro aspecto que parece diferenciar e colocar em lados opostos As Regras do Método Sociológico e As Formas Elementares, relacionado com as concepções que fundamentam o método recém descrito (em parte), é o alegado positivismo de Durkheim presente na primeira obra e ausente na segunda. Até que ponto tal interpretação é pertinente?

\footnotetext{
5 "O método trabalhado em As Formas Elementares encontra-se ainda mais distanciado dos enunciados metódicos formulados em As Regras. O conhecimento dos materiais não é senão indireto, sendo fornecido pela a enquete de Spencer e Gillen sobre as tribos australianas e, sobretudo, Durkheim toma então só um caso para fundar toda sua construção. Portanto, a questão do método comparativo não pode estar presente neste livro..." (Steiner, 2005, p. 42).
} 
Antes de respondermos a esta pergunta, urge discutir, ainda que brevemente, sobre o propalado positivismo de Durkheim. De fato, como bem ressalta Heilbron (1985), Durkheim não desconhece e até incorpora as contribuições de Comte para a questão da especificidade da sociologia enquanto ciência.

Contudo, para além desse aspecto, quando lançamos um olhar percuciente sobre o conjunto da obra de Durkheim, a linha de continuidade em relação a Comte claudica inapelavelmente. Embora existam muitos aspectos que corroboram a interpretação aqui proposta, destacarei apenas três, para voltarmos logo ao nosso tema central. Primeiro, Durkheim não incorpora a ideia de harmonia entre as partes que compõem a vida social nem a tendência comtiana de perder de vista as determinações históricas da sociedade. Um bom exemplo disso é o artigo $O$ individualismo e os intelectuais (Durkheim, 1987), no qual o autor ressalta a individualidade como uma característica da modernidade e os conflitos que ela implica. Segundo, embora algumas vezes negue, Durkheim muito deve aos alemães o modo como elabora suas explicações sobre a vida social. Terceiro, a concepção da vida social adotada por Durkheim, antes de ser comtiana, é extraída criticamente de Immanuel Kant; a importância atribuída à moral para a existência da vida social, que ele encontra e aprende na Escola Normal Superior, evidencia isso. Não só. Como mostram as pesquisas de Raquel Weiss, "os argumentos que dizem respeito à obra kantiana encontram-se espalhados por todos os seus escritos sobre a moral, muitas vezes aparecem de forma indireta". É por isso que, segundo ainda essa autora, "a filosofia de Kant não deve ser entendida apenas como um contraponto crítico da teoria moral durkheimiana, mas também como uma influência de grande importância" (Weiss, 2011, pp. 137-138).

Essas ponderações acerca do distanciamento de Durkheim em relação ao positivismo permitem, agora, discutirmos o idealismo que é atri- 
buído a As Formas Elementares, por motivos diferentes, tanto por Parsons quanto por Cuvillier, e que serve para diferenciar esta obra de As Regras do Método Sociológico.

Para Parsons, esse idealismo - algo que ele considera positivo - pode ser identificado no aspecto de Durkheim não mais tratar os fenômenos sociais como coisa, e em razão da determinação social das categorias, já que, por social, segundo ele, Durkheim entende - em As Formas Elementares - um conjunto de valores. Ora, é importante lembrar que, em respostas às críticas dirigidas a As Regras do Método Sociológico, seu autor esclarece - no Prefácio da Segunda Edição - que esta regra não se trata da defesa de um empirismo vulgar. Segundo ele,

Não afirmamos que os fatos sociais são coisas materiais..., [pois por coisa deve-se entender] todo objeto do conhecimento que não é naturalmente penetrável à inteligência, tudo aquilo de que não podemos ter uma noção adequada por um simples procedimento de análise mental... Tratar certos fatos como coisas não é, portanto, classificá-los numa ou noutra categoria do real; é ter para com eles uma certa atitude mental; é abordar o seu estudo partindo do princípio de que se desconhece por completo o que eles são e que suas propriedades características, tal como as causas de que dependem, não podem ser descobertas pela introspecção, por mais atenta que seja (Durkheim 1963, p. 10).

Este modo de tratar o objeto de estudo não se modifica substancialmente em As Formas Elementares. De fato, aí, Durkheim defende que, no estudo da religião, convém ao pesquisador colocar-se no estado de espírito do crente. Contudo, ele continua a insistir que, para a produção de um conhecimento verdadeiramente sociológico, urge não perder de vista a objetividade do fenômeno social em questão, nem, muito menos, deixar de buscar sua causa. Quanto à origem das categorias do conhecimento, de fato, Durkheim as identifica na sociedade, onde as representações são fundamentais. Contudo, Parsons esquece que Durkheim nunca perde de 
vista a relação existente entre esses valores (ou representações) e os fatos de ordem morfológica; ainda que surjam novas representações, como as categorias de espaço, tempo, espécie, etc., geradas no interior das representações primárias, suas autonomias têm de ser relativizadas. Como argumenta Durkheim na conclusão de As Formas Elementares, ao longo da história, essas categorias se depuram, "elas necessitam ser organizadas segundo princípios que lhes sejam próprios" (Durkheim, 1968, p. 635), mas nem por isso deixam de ter uma origem social.

A ênfase de Durkheim sobre a origem social das categorias do Conhecimento é útil para analisarmos o idealismo que também Armand Cuvillier lhe imputa, a partir de fins do século XIX. De que modo Cuvillier chega a esta compreensão? No seu texto Durkheim et Marx, de 1948, ele estabelece um estudo comparativo entre os dois pensadores, no qual, dentre vários aspectos discutidos, tenta traçar um paralelo entre o conceito de superestrutura e o conceito de consciência coletiva. Segundo ele, apesar da diversidade teórica entre os dois pensadores, esses conceitos não só se assemelham na origem e no modo como são utilizados, como também evidenciam um distanciamento de seus formuladores do idealismo. No entanto, para Cuvillier, na passagem do século XIX para o XX, com a publicação do texto Representações individuais e representações coletivas, uma vez que estas últimas tendem a perder o contato com a dimensão morfológica e passam a ser explicadas por outras representações, Durkheim foi tendendo e acabou por sucumbir ao idealismo. Cuvillier esquece que, ao longo do período em que ele identifica o idealismo de Durkheim e que deságua em As Formas Elementares, este reiteradamente, por exemplo, elabora uma crítica a Immanuel Kant; A determinação do fato moral expressa claramente isso. Assim, como mostrado na introdução dessa obra, enquanto Kant concebe as categorias de tempo, espaço, gênero, espécie, etc., como estruturas cognitivas universais e, por isso, 
atemporais, para Durkheim elas têm uma origem social e, por conseguinte, são históricas. Não só. Segundo Durkheim, a admissão da origem social das categorias é a solução tanto para o apriorismo, como também para o empirismo (Durkheim, 1968, p. 21).

Essas considerações permitem afirmar que, apesar da individualidade de cada livro, parece ser questionável pensarmos que a última grande obra publicada em vida por Durkheim represente uma ruptura em seu projeto e trajeto intelectual. Na verdade, é mais plausível asseverar que há, indubitavelmente, dos pontos de vista teórico e metodológico, um liame nada desprezível que vincula As Formas Elementares às obras anteriores; ou levar em conta que, como pondera Ortiz, "o problema é entender em que medida se dá a reorganização das ideias e dos conceitos, situando-os, porém, no interior da perspectiva global [de Durkheim], pois as continuidades existem e permeiam inclusive os estudos sobre os "longínquos" povos primitivos" (Ortiz, 2008, p.7).

Por último, retomemos o problema sobre o abandono da questão social, que é identificado por Bernard Lacroix e Béatrice Landerer. Aparentemente, esta parece ser a crítica mais difícil de rebater, no que se refere à tese da descontinuidade entre as primeiras obras e As Formas Elementares. Tudo leva a crer que, a partir da revelação de 1895, que desaguaria na publicação do livro, tal questão não caberia mais no horizonte das preocupações de Durkheim. Para verificarmos a pertinência dessa interpretação, propomos discutir e esclarecê-la em dois níveis.

Primeiro, mesmo en passant, não podemos esquecer que, no período referido por Lacroix e Landerer, Durkheim de alguma forma engajou-se em várias discussões e campanhas públicas. Além do Caso Dreyfus, ele participou ativamente na luta contra a Primeira Guerra. Ao mesmo tempo, reiterando suas posições das duas últimas décadas do século XIX, ele continuou fazendo críticas contundentes à economia liberal. Poucos meses antes de morrer, por exemplo, instado pelo jornal La Dépêche de 
Toulouse a responder sobre o futuro da política, ele defende que, ao contrário da crença quase religiosa dos economistas no mercado, após a guerra, a economia deveria ser controlada e regulamentada pelo governo. A certa altura do artigo, tomando como referência Saint-Simon e as doutrinas socialistas, Durkheim afirma: "a atividade econômica é coisa eminentemente social, ela visa fins sociais, interesses sociais, e, consequentemente, ela tem a necessidade de ser 'socialmente organizada'" (Durkheim, 2011, p.229). Ou seja, ao contrário da crítica, esta passagem mostra que a questão social não havia desaparecido dos horizontes de Durkheim.

Saindo do plano mais pessoal, num segundo nível, podemos seguramente encontrar um melhor esclarecimento da relação de As Formas Elementares com a questão social no significado contido na própria publicação dessa obra. Assim, a chave para essa elucidação aparentemente pode ser buscada na grande pesquisa desenvolvida anteriormente pelo autor e, por conseguinte, no seu livro precedente. Renato Ortiz, em Durkheim: arquiteto e herói fundador, defende que o estudo do suicídio foi estratégico na luta pela afirmação da sociologia, na medida em que produziu uma explicação desse fenômeno diferente das formuladas pela psicologia (Ortiz, 1989, p.16). Ao que tudo indica, o estudo da religião também tem algo de estratégico nesse sentido. Na verdade, podemos inseri-lo no seio da questão social, pois, de algum modo, ele enfrenta o poder e, por isso, a influência que a Igreja ainda exercia sobre a vida social francesa; a própria direita católica era crítica e abominava a sociologia produzida por Durkheim (Lepenies, 1990, pp. 74-75). Este, com As Formas Elementares, apesar de reconhecer a permanência e a importância social da religião, desenvolve um estudo científico desse fenômeno e mostra que, na sociedade moderna, a religião perdeu definitivamente sua função cognitiva; ou seja, afirma-se o conhecimento científico. Essa posição, embora não fosse essa a intenção do seu autor, reforçava, por exemplo, a laicidade da educação, algo importante e tratado com zelo pela Terceira República e 
que era defendido e posto em prática pelo autor nos cursos que ministrava para os professores, principalmente os do ensino primário, desde o início de sua docência em Bordeaux, em 1887, até seu prosseguimento em Paris, na Sorbonne, a partir de $1902 .{ }^{6}$ Não por acaso, ele faz a seguinte afirmação logo no segundo parágrafo do livro:

A sociologia coloca problemas outros que aqueles da história e da etnologia. Ela não procura conhecer as formas antigas da civilização com a única finalidade de conhecê-las e reconstituí-las. Diversamente, como toda ciência positiva, ela tem, antes de tudo, por objeto, explicar a realidade atual, próxima de nós, capaz, por conseguinte, de afetar nossas ideias e nossos atos: essa realidade é o homem e, mais especialmente, o homem de hoje, pois não há outro que estejamos mais interessados em bem conhecer. Portanto, não estudaremos a religião mais arcaica, que vai ser objeto de questionamentos, pelo simples prazer de contar suas bizarrices e singularidades (Durkheim, 1968, pp. 1-2).

A partir do exposto acima, é possível afirmar que, para não perdemos de vista sua riqueza, As Formas Elementares da Vida Religiosa deve ser compreendida como uma obra que se encontra no interior de um coerente projeto intelectual. Isso porque, como vimos, ela foi gradativamente maturada, precedida por uma série de estudos relacionados ao objeto, o que levou à substituição de determinados conceitos, ao refinamento de outros, e à redefinição do autor em relação ao papel do fenômeno religioso no conjunto da vida social. Não só. Todo o longo caminho para a sua realização foi feito sob a égide da sociologia, que o autor buscava afirmar no cenário acadêmico-científico francês. Avaliamos que esta é uma maneira, por paradoxal que possa parecer a afirmação, de se entender a individualidade e a originalidade desse último livro que Émile Durkheim publicou em vida.

${ }^{6}$ Segundo Fauconnet, Durkheim "sempre dedicou, semanalmente, uma hora de aula à pedagogia. Seus ouvintes eram, sobretudo, professores do ensino primário". (Fauconnet,1999, p. 11). 
José Benevides Queiroz - Professor do Programa de Pós-Graduação em Ciências Sociais da Universidade Federal do Maranhão. $\backslash$ jbenevidesq@ufma.br

\section{Referências}

1. ARON, R. As Etapas do Pensamento Sociológico, 5a edição, São Paulo: Martins Fontes, 1999.

2. ARON, R. La Sociologie Allemande Contemporaine, Paris: Alcan, 1936

3. BACIOCCHI, S. Les recensions des Formes du vivant de leur auter (1912 1917). Archives de Sciences Sociales des Religions, n. 159, Paris: Éditions de EHESS, juillet-septembre 2012.

4. CUVILLIER, A. Durkheim et Marx. Cahiers Internationaux de Sociologie, v. IV, Paris, 1948.

5. DURKHEIM, É. Sociologia religiosa e teoria do conhecimento. Revista Pós Ciências Sociais, v. 10, n. 19, São Luís: EDUFMA, 2013.

6. DURKHEIM, É. A política de amanhã. Tradução e introdução por José Benevides Queiroz. Perspectivas: Revista de Ciências Sociais, v. 40, São Paulo: UNESP, 2011.

7. DURKHEIM, É. Détermination du fait moral in Sociologie et Philosophie, $2^{\mathrm{e}}$ edition, Paris: PUF/Quadrige, 2002.

8. DURKHEIM, É L'individualisme et les intellectuels in La Science Sociale et L'Action, 2 $2^{\mathrm{e}}$ edition, Paris: PUF, 1987.

9. DURKHEIM, É. De L'irréligion de L'avenir. Textes II (Religion, Morale, Anomie), Paris, Les Editions Minuit, [1887] 1975a.

10. DURKHEIM, É. Lettres à Octave Hamelin (29/06/1901). Textes II, 1975b.

11. DURKHEIM, É. La Sociologie en France (1895) in Textes I (Éléments D'une Théorie Sociale), Paris, Les Editions Minuit, [1895] 1975c.

12. DURKHEIM, É. Deux lettres sur l'influence Allemande dans la sociologie française. Réponse a Simon Déploige. Textes I, [1907] 1975d.

13. DURKHEIM, É. Représentations individuelles et représentations collectives in Sociologie et Philosophie. Textes II,1975e.

14. DURKHEIM, É. Textes I (Éléments D’une Théorie Sociale), Paris, Les Editions Minuit, $1975 f$.

15. DURKHEIM, É. Textes II (Religion, Morale, Anomie), Paris, Les Editions Minuit, $1975 \mathrm{~g}$ 
16. DURKHEIM, É. Les Formes Élémentaires de la Vie Religieuse, $5^{e}$ édition, Paris: Quadriage/PUF, 1968.

17. DURKHEIM, É. Les Règles de la Méthode Sociologique, $15^{e}$ édition, Paris, PUF, 1963.

18. FAUCONNET, P. L'oeuvre pédagogique de Durkheim. In: DURKHEIM, E. Education et Sociologie, 7e édition, Paris: Quadriage,PUF, 1999.

19. GIDDENS, A. As Ideias de Durkheim, São Paulo: Cultrix, 1981.

20. HEILBRON, J. Les metamorphoses du durkheimisme, 1920 - 1940. Revue Française de Sociologie, v. XXVI, Paris, 1985, pp. 203-237.

21. LACROIX, B.; LANDERER, B. Durkheim, Sismondi et les socialistes de la chaire. L'Année Sociologique, no 23, Paris: PUF, 1972.

22. LEPENIES, W. Les Trois Cultures. Paris: Ed. De la Maison des Sciences de L'homme, 1990.

23. MARCEL, J-C. Le Durkheimisme Dans L'entre-deux-guerres, Paris: PUF, 2001.

24. ORTIZ, R. Durkheim: um percurso sociológico. In: DURKHEIM, É. As Formas Elementares da Vida Religiosa, 3a edição, São Paulo: Paulus, 2008.

25. ORTIZ, R. Durkheim: arquiteto e herói fundador. Revista Brasileira de Ciências Sociais, v. 4, n. 11, 1989.

26. PARSONS, T. A Estrutura da Ação Social, v. I, Petrópolis: Vozes, 2010.

27. STEINER, P. La Sociologie de Durkheim, $4^{e}$ édition, Paris: La Découverte, 2005.

28. WEISS, R. Émile Durkheim e a revolução copernicana no conceito de moral. In OLIVEIRA, M.; WEISS, R. (Orgs.) David Émile Durkheim: a Atualidade de Um Clássico, Curitiba: Ed. UFPR, 2011.

Recebido: 27.09.16

Aceito: 10.01.17 